\title{
Gender Differences in the Behavioral Responses to Cocaine and Amphetamine
}

\section{Implications for Mechanisms Mediating Gender Differences in Drug Abuse}

\author{
JILL B. BECKER, HEATHER MOLENDA, ${ }^{a}$ AND DANIEL L. HUMMER
}

Psychology Department, Reproductive Sciences Program, and Neuroscience Program, The University of Michigan, Ann Arbor, Michigan 48109, USA

\begin{abstract}
When ovariectomized female rats receive estrogen, the response to the psychomotor stimulants amphetamine or cocaine is enhanced. Estrous cycle-dependent differences in amphetamine-stimulated behaviors and striatal dopamine release are also noted. Intact female rats exhibit a greater behavioral response to amphetamine on estrus than they do on other days of the cycle. Ovariectomy results in attenuation of amphetamine-induced behavior and the striatal dopamine response to amphetamine. Physiological doses of estrogen given to ovariectomized rats reinstate both of these responses to a level comparable to that in estrous females. Furthermore, a sex difference is noted, in that females tend to exhibit a greater behavioral response to the psychomotor stimulants, and estrogen enhances this sex difference. Repeated treatment with amphetamine or cocaine produces a progressive increase in behavioral responsiveness with subsequent drug administration, a process known as sensitization. In rodents, behavioral sensitization results in increases in both frequency and duration of psychomotor behaviors such as rotational behavior, stereotyped grooming, headbobs, and forelimb movements. Interestingly, females display greater sensitization of behaviors in response to psychomotor stimulants than do males. Previous research results are summarized, and new results are presented, demonstrating that estrogen selectively enhances components of behavior that exhibit sensitization in female rats. Results also indicate gender differences in sensitization independent of gonadal hormones, suggesting that the neural systems that undergo sensitization are sexually dimorphic.
\end{abstract}

Keywords: Amphetamine; Cocaine; Drug abuse; Gender differences in drug abuse; Ovariectomy; Psychomotor stimulants

${ }^{a}$ Current affiliation: University of Massachusetts, Department of Psychology, Amherst, Massachusetts.

Address for correspondence: Jill B. Becker, Psychology Department, Biopsychology Area, 525 East University, Ann Arbor, MI 48109-1109. Voice: 734-763-4363; fax: 734-763-7480.

jbbecker@umich.edu 


\section{INTRODUCTION}

The use of all illicit drugs has been increasing among women in the last decade. In particular, cocaine dependence among women is a growing public health concern. ${ }^{1}$ While males have historically been seen as the primary users of illicit drugs, $9 \%$ of women over the age of 12 have used cocaine. Marijuana is the only illicit drug used more frequently by women ( $28 \%$ have used marijuana). ${ }^{2}$ Of particular concern is the finding that women are more likely to become addicted to cocaine, if they have used it, than to any other drug. Among the women who have used cocaine, the prevalence of lifetime dependence is $14.9 \pm 2.0 \%$ (mean \pm SD). By contrast, $79 \%$ of women have used alcohol, but only $9.2 \pm 0.8 \%$ have developed lifetime dependence. ${ }^{2}$ With gender differences in the use of illicit drugs diminishing, it is necessary to consider whether gender differences exist in the neural mechanisms mediating the effects of cocaine and the likelihood of becoming addicted to this drug.

We know that there are gender differences in some of the acute subjective responses to psychomotor stimulant drugs. ${ }^{3}$ In a recent study of the acute subjective effects of amphetamine (AMPH) in women, higher levels of estrogen were associated with greater AMPH-induced increases in "euphoria" and "energy and intellectual efficiency." 3 Gender differences and significant effects of the menstrual cycle on peak plasma cocaine were also noted after intranasal administration. ${ }^{4}$ Furthermore, the pattern of cocaine use and the onset of addiction to cocaine are more rapid in women than in men. ${ }^{5}$

As evident from a review of the animal literature which follows, results in humans parallel, to some extent, those in rodents. Here, female rats exhibit a greater initial behavioral response to AMPH or cocaine and show an even greater rate of enhanced behavioral response to subsequent treatments (i.e., sensitization) than do males. Basic research on the role of gender and ovarian hormones in the response to acute and repeated exposure to cocaine and AMPH may enhance our understanding of the processes involved in gender differences in drug abuse. The Becker laboratory has been investigating how estrogen acts in the striatum of the rat to affect the neurotransmitter dopamine (DA) and the behavioral responses to psychomotor stimulant drugs.

The ascending DA projection from the midbrain to the dorsal and ventral striatum is a massive projection, within which over $90 \%$ of the DA in the brain resides. ${ }^{6}$ Administration of drugs that activate or inhibit DA systems induces behaviors that are due primarily to activity in this ascending DA system. Investigated behaviors, that is, rotational behavior or stereotyped behaviors, have been shown to be mediated primarily by the nigrostriatal DA system. ${ }^{7-11}$ Thus, these behaviors can be used as an index, or behavioral assay, of DA activity in the striatum. 
For example, a low dose of AMPH induces rotational behavior in rats due to endogenous asymmetry in the nigrostriatal DA system. ${ }^{12}$ When males are given a dose of $1.56 \mathrm{mg} / \mathrm{kg}$ AMPH and females receive $1.25 \mathrm{mg} / \mathrm{kg}$ AMPH (to overcome gender differences in AMPH metabolism), striatal concentrations of AMPH are equivalent during the behavioral testing period, but male rats turn significantly less than do female rats at all stages of the estrous cycle except for metaestrus. ${ }^{13}$ In this experiment, animals were tested during the dark phase of the light:dark cycle, and ovarian hormones were at their lowest during metaestrus. A role for ovarian hormones in modulating rotational behavior is demonstrated by the finding that gonadectomy results in a significant decrease in rotational behavior in female, but not male rats. In fact, after ovariectomy (OVX) there is a decrease in rotational behavior induced by either AMPH or unilateral electrical stimulation of the ascending DA projection to the striatum behavior. ${ }^{14,15}$ In the same experiments, there was no effect of castration in male rats on rotational behavior. ${ }^{14,15}$ Thus, the effect of OVX to attenuate the behavioral response to and the gender differences induced during DA activation are not unique to the effect of AMPH, but are apparently more general properties of the ascending DA system.

Selective hormone replacement experiments demonstrate that estrogen alone is sufficient to enhance rotational behavior in the ovariectomized female rat. ${ }^{16}$ Importantly, while rotational behavior or stereotyped behavior is enhanced by repeated estrogen treatment (hormone treatment to approximate estrogen exposure during the estrous cycle), a single dose of $5 \mu \mathrm{g}$ estradiol benzoate (EB) 30 minutes prior to AMPH is sufficient to induce a significant increase in AMPH-induced behaviors. ${ }^{17,18}$ Thus, acute estrogen treatment rapidly induces an increase in behavioral measures of nigrostriatal DA activity. This is an important point, as it suggests that the mechanism mediating the effect of estrogen in the striatum is different from that mediated by classical estrogen receptors, which usually take hours to days to produce changes in behavior.

Furthermore, in vivo microdialysis to determine extracellular concentrations of DA in striatum indicates estrous cycle-dependent variation in the AMPH-induced increase of DA in striatum. Female rats during estrus have a significantly greater AMPH-induced increase in extracellular DA in striatum than do female rats during metaestrus. ${ }^{19}$ During microdialysis in the same animals, females in estrus exhibited significantly more stereotyped behavior than did animals in metaestrus. ${ }^{19}$ In addition, a single dose of $5 \mu \mathrm{g}$ EB given to ovariectomized rats enhances the AMPH-induced increase in extracellular striatal DA coincident with enhanced rotational behavior. ${ }^{17}$ The effect of acute estrogen treatment to enhance AMPH-induced DA in striatum and $\mathrm{AMPH}$-induced behaviors is found in ovariectomized female rats but not in 
castrated male rats. ${ }^{20}$ Thus, a sex difference exists in the effect of estrogen in the striatum.

The results of the microdialysis experiments lead to the question of whether the effects of estrogen on DA-mediated behaviors cause the effects on striatal DA release just described or whether the effects of estrogen on striatal DA release induce the reported effects on behavior. Experiments to examine DA release from striatal tissue in vitro can be used to demonstrate the causal relation between these events. Using an in vitro superfusion system to study DA release from striatal tissue, we have confirmed that: (1) AMPH-induced striatal DA release varies with estrous cycle ${ }^{21}$; (2) OVX attenuates AMPHinduced striatal DA release, whereas castration of male rats has no effect on this measure ${ }^{21,22}$; and (3) estrogen treatment enhances AMPH-stimulated striatal DA release in striatal tissue from female but not male rats. ${ }^{21,22}$ From these experiments we conclude that the effects of estrogen on striatal DA release occur in the absence of behavior. Thus, the effects of estrogen on striatal DA release likely mediate the changes in behavior that occur.

With an in vitro superfusion system estrogen can be delivered directly to striatal tissue slices to determine whether it is acting directly on the striatum to produce its effects on the striatum. Thus, it is an important finding that estrogen in physiological concentrations $(100 \mathrm{pg} / \mathrm{ml})$ acts directly on the striatum of ovariectomized female rats to enhance AMPH- or K+-stimulated DA release. ${ }^{21,23}$ Furthermore, the pulsatile administration of estrogen directly stimulates DA release in striatal tissue from female rats, but not male rats. ${ }^{21}$ These results indicate that the acute effects of estrogen on striatal DA and on DA-mediated behavior are most likely due to the direct effects of estrogen on the striatum.

Experiments using whole-cell clamp electrophysiology in acutely dissociated striatal neurons support the idea of rapid, direct effects of estrogen in the striatum. Estrogen inhibits L-type $\mathrm{Ca}^{2+}$ channels in striatal neurons. ${ }^{24}$ The effects occur within seconds, reverse as soon as estrogen delivery ceases, and are seen at physiological concentrations of estrogen (i.e., pM). Furthermore, cells from females show a greater response than do cells from the striatum of males. Estrogen conjugated to a large protein to prevent the entry of estrogen into the cell is also effective. In addition, estrogen applied internally to cells through the electrode is not effective in reducing $\mathrm{Ca}^{2+}$ currents and does not block the effect of $1 \mathrm{pM}$ estrogen applied externally. Collectively, these results suggest that the effect of estrogen occurs externally at the membrane surface. In the presence of GTP $\gamma \mathrm{S}$ (which prevents inactivation of G-protein mediated events), the effect of $17 \beta$-estradiol does not reverse when hormone delivery ceases. Thus, the effect of estrogen on striatal neurons apparently de- 
pends on a G-protein-coupled receptor. Finally, the effect of $17 \beta$-estradiol is stereospecific, as $17 \alpha$-estradiol does not mimic the modulation, and steroidspecific as $100 \mathrm{pM}$ estrone and 3-methoxyestriol were ineffective while estriol or 4-hydroxy-estradiol mimic the effect of $17 \beta$-estradiol. These results indicate, therefore, that estrogen has rapid stereospecific effects on striatal neurons that alter signaling pathways independent of the classical estrogen receptor. ${ }^{24}$

\section{BEHAVIORAL SENSITIZATION}

Gender differences in and hormonal influences on the acute effects of the psychomotor stimulants are just part of the complex way in which these drugs act in the brain. The reason is that the effects of cocaine and AMPH change with repeated administration. These changes take two general forms: tolerance or sensitization. ${ }^{25,26}$ Tolerance, and its role in the development of physical dependence, has been a focus of addiction research for many years. ${ }^{25,27-}$

${ }^{30}$ More recently, the role of sensitization-related neuroadaptations in the process of addiction has become an important area of research as well. ${ }^{26,31-39}$

Behavioral sensitization refers to an increase in drug effect with repeated drug administration. Although most drug effects do not undergo sensitization, two major classes do: the psychomotor stimulant effects and the incentive motivational or rewarding effects of these drugs. The psychomotor stimulant effects that show sensitization include locomotor hyperactivity, stereotyped behavior, and rotational behavior. ${ }^{40-42}$ The association between sensitization and addiction is indicated by the influence of prior drug exposure on the later acquisition of a conditioned place preference ${ }^{35,43-45}$ or drug self-administration behavior. ${ }^{33,34,36,46-50}$ The results of these and other studies suggest a relationship between drug-seeking behavior and drug sensitization.

One of the most remarkable features of sensitization is its persistence. Sensitization to AMPH, cocaine, or morphine has been reported to last weeks to months following the discontinuation of pretreatment. ${ }^{51}$ Furthermore, sensitization to treatment with escalating doses of AMPH persists at least a year in the rat. ${ }^{52}$ With some treatment regimens, however, the persistence of cocaine sensitization may be much more transient. ${ }^{53-55}$ Sensitization has been the topic of a number of review articles to which the reader is referred for additional information (e.g., Refs. 40, 41, and 56-61). It is beyond the scope of this article to provide a complete treatment of the topic. 


\section{GENDER DIFFERENCES IN SENSITIZATION TO PSYCHOMOTOR STIMULANTS}

Female rats generally exhibit more robust sensitization in response to AMPH (i.e., a greater absolute increase in psychomotor behavior) than do intact males. ${ }^{42,62-66}$ Although the effects of AMPH sensitization studies are confounded by gender differences in AMPH metabolism, gender differences persist even when males are given higher doses of AMPH to produce comparable brain AMPH concentrations. ${ }^{42,62-66}$ One study reported gender differences in sensitization of AMPH-induced rotational behavior at a high dose of AMPH, but not a low dose. ${ }^{42}$ This suggests gender differences in the doseeffect curve for the induction and/or expression of sensitization, but very little research has investigated or even characterized sex differences in sensitization.

Most studies have reported that OVX in female rats does not affect the induction or expression of sensitization to AMPH. ${ }^{42,62-64,66}$ However, estrogen treatments in ovariectomized rats enhance sensitization of locomotor activity induced by AMPH. ${ }^{66}$ Thus, variability in the behavior of intact female rats across the estrous cycle may obscure the effects of ovarian hormones on the induction and/or expression of sensitized psychomotor behaviors in experiments in which intact and ovariectomized rats are compared.

Castration (CAST) of male rats has been reported to enhance sensitization of AMPH-induced psychomotor behavior relative to intact males, ${ }^{42,62,63}$ but not all investigators have found this result. ${ }^{66}$ If CAST enhances the induction and/or expression of behavioral sensitization due to the removal of gonadal steroid hormones, then testosterone treatment should reverse this effect. This is not the case, however, as testosterone treatment does not suppress behavioral sensitization in castrated male rats. ${ }^{66}$ (Our own unpublished data confirm this as well.) Thus, the role of testicular hormones in sensitization to psychomotor stimulants remains an open question.

Research on gender differences in the sensitization of cocaine-induced behavioral activity is less problematic than is AMPH sensitization, as brain concentrations of cocaine afater peripheral metabolism are the same in males and females ${ }^{67}$ and here again females exhibit greater behavioral sensitization. ${ }^{65}$ However, ovariectomized females have been reported not to show sensitization of cocaine-induced locomotor activity when intact females or gonadal hormone treated females do. ${ }^{55,65,68}$

In the Becker laboratory we have been investigating the role of gonadal steroid hormones in behavioral sensitization and here describe the preliminary results of two ongoing studies. The results of these studies illustrate two important points with regard to gender differences in behavioral sensitization to 
cocaine and the role of gonadal hormones in modulating sensitization. First, we find gender differences in and hormonal influences on the specific behaviors that undergo behavioral sensitization. Second, estrogen enhances sensitization of the female-specific behaviors in females rats, but not in males.

\section{EXPERIMENT 1. GENDER DIFFERENCES IN SENSITIZATION OF STEREOTYPED BEHAVIORS}

In one study the influence of gonadal hormones on the development of sensitization of stereotyped behaviors induced by cocaine was investigated in adult male and female Sprague-Dawley rats. Four groups were compared: ovariectomized (OVX; $n=10$ ) females, ovariectomized females treated with $16 \mu \mathrm{g} / \mathrm{kg}$ estradiol benzoate (OVX $+\mathrm{EB} ; n=11)$, castrated (CAST; $n=11)$ males, and SHAM castrated intact males (SHAM; $n=10$ ). Surgery was performed under pentobarbital anesthesia at least 2 weeks prior to the behavioral tests. On test days, all animals received an injection of $0.1 \mathrm{ml}$ peanut oil (s.c.) 30 minutes prior to cocaine, except for the OVX + EB group that received $16 \mu \mathrm{g} / \mathrm{kg}$ EB in $0.1 \mathrm{ml}$ peanut oil (s.c.). Cocaine ( $15 \mathrm{mg} / \mathrm{kg}$ i.p.) was then administered. Animals were videotaped for 30 minutes before and 30 minutes after cocaine. Animals were tested for 4 consecutive days followed by 3 days without treatment, for a period of 3 weeks (12 test days). Behaviors were scored from videotape by an observer blind to the treatment group. The numbers of headbobs, forelimb movements, and midline crossings were counted for 10 seconds every 5 minutes during the 30 minutes before injection and for 30 minutes after cocaine or saline injection. The totals for each type of movement were used for analyses. The results of the first and last days of testing are reported here.

As illustrated in FIGURE 1, the groups did not differ significantly on any of the behaviors on day $1(p>0.05)$, but exhibited different profiles of sensitization for forelimb movements, midline crosses, and headbobs. For forelimb

FIGURE 1. Stereotyped behaviors induced by $15 \mathrm{mg} / \mathrm{kg}$ cocaine (i.p.) show different patterns of sensitization depending on the gender and gonadal hormone condition of the rat. Forelimb movements (top panel): Female rats exhibit greater sensitization than do male rats, and estrogen treatment further enhances sensitization of ovariectomized females (*significantly greater than CAST and SHAM groups, $p$ $<0.05)$; **significantly greater than all other groups, $p<0.001)$. Midline Crosses (middle panel): SHAM males did exhibit sensitization of midline crosses, while the other groups did. (*behavior on day 12 significantly greater than that of the SHAM male group, $p<0.05$ ). Headbobs (bottom panel): $*$ SHAM and CAST males showed an increase in headbobs with repeated exposure to cocaine $(p<0.05)$; the other groups did not. 

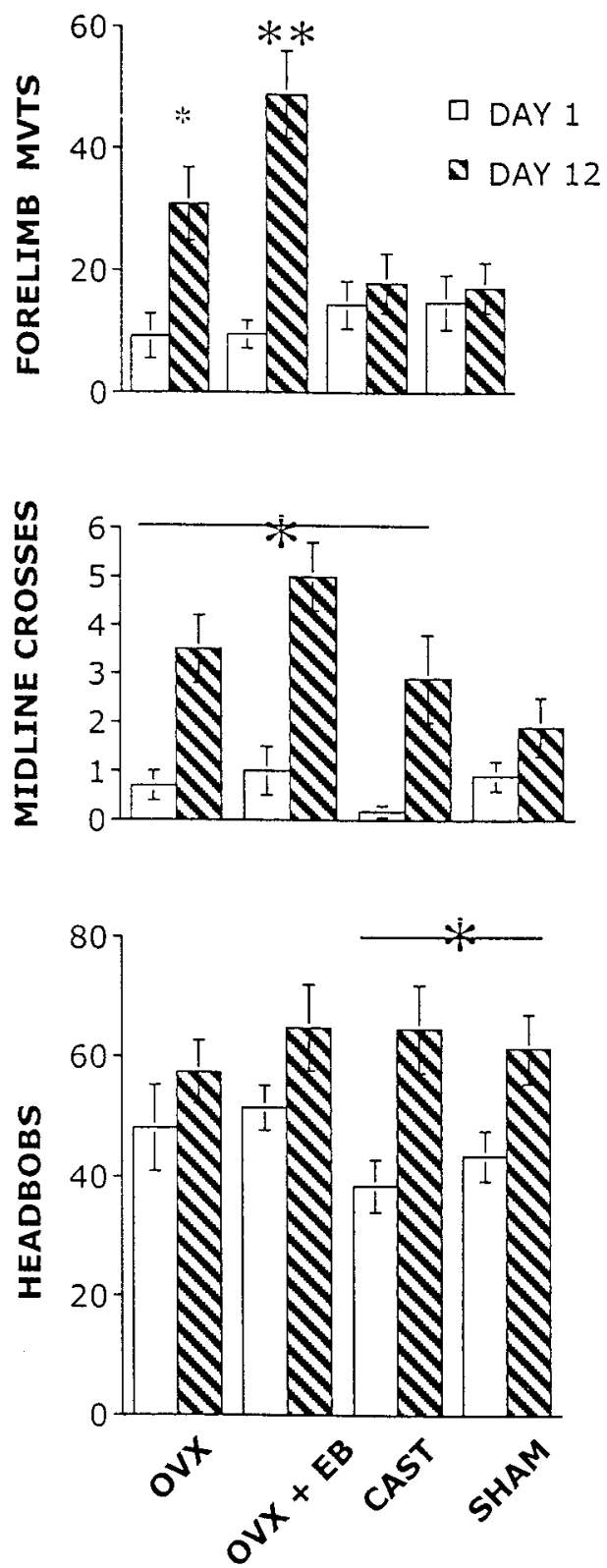

GROUP

FIGURE 1. See previous page for legend. 
movements (top panel) there was a significant group effect on day $12(\mathrm{~F}(3,38)$ $=6.79 ; p<0.001)$, with the OVX $+\mathrm{EB}$ group exhibiting more forelimb movements than did any other group $(p<0.05)$. On paired $t$ tests within each group, only the OVX + EB and OVX groups exhibited an increase in forelimb movements as a result of repeated cocaine treatment when day 1 and day 12 were compared $(p<0.005)$. In terms of the magnitude of the increase in forelimb movements (day 12 minus day 1) there was a significant effect of group $(\mathrm{F}(3,38)=8.297, p<0.001)$, indicating group differences in sensitization. In post-hoc tests, the OVX + EB group showed greater sensitization than did the other three groups ( $p<0.001$ vs CAST or SHAM males; $p<0.05$ vs OVX), and the OVX group exhibited greater sensitization than did the CAST or SHAM male groups $(p<0.05)$.

For midline crosses (center panel) there was also a significant effect of group on day $12(\mathrm{~F}(3,38)=3.37 ; p<0.03)$, with the OVX + EB group exhibiting more forelimb movements than did either of the male groups $(p<0.05)$. On paired $t$ tests within each group (day 1 vs day 12), the OVX + EB, OVX, and CAST groups exhibited an increase in midline crosses as a result of repeated cocaine treatment $(p<0.01)$, whereas the SHAM males did not $(p=0.117)$.

For headbobs (bottom panel) there was no effect of group on day 12 $(\mathrm{F}(3,38)=0.394)$. On paired $t$ tests within each group (day 1 vs day 12$)$, only the CAST and the SHAM male groups exhibited an increase in headbobs as a result of repeated cocaine treatment $(p<0.005)$. Repeated saline treatment had no effect on any measure (data not shown).

Thus, estrogen treatment enhanced sensitization of forelimb movements, but it did not affect locomotor behavior or headbobs. Furthermore, a sex difference was noted in the absence of gonadal hormones in sensitization of forelimb movements. By contrast, when headbobs were examined, the male groups exhibited sensitization, whereas the female groups did not. Finding that there are gender differences in sensitization that are independent of gonadal hormones suggests that there may be organizational effects of gonadal hormones on the neural systems mediating sensitization.

\section{EXPERIMENT 2. GENDER DIFFERENCES IN SENSITIZATION OF ROTATIONAL BEHAVIOR}

In a second study, animals received unilateral 6-hydroxydopamine lesions of the substantia nigra ${ }^{69}$ and 2 weeks later were ovariectomized or castrated under pentobarbital anesthesia. Ovariectomized and castrated animals were treated with $16 \mu \mathrm{g} \mathrm{EB} / \mathrm{kg}$ or peanut oil as described above 30 minutes before receiving $15 \mathrm{mg} / \mathrm{kg}$ cocaine (OVX $+\mathrm{EB}, n=12 ; \mathrm{OVX}+\mathrm{OIL}, n=10 ; \mathrm{CAST}$ 


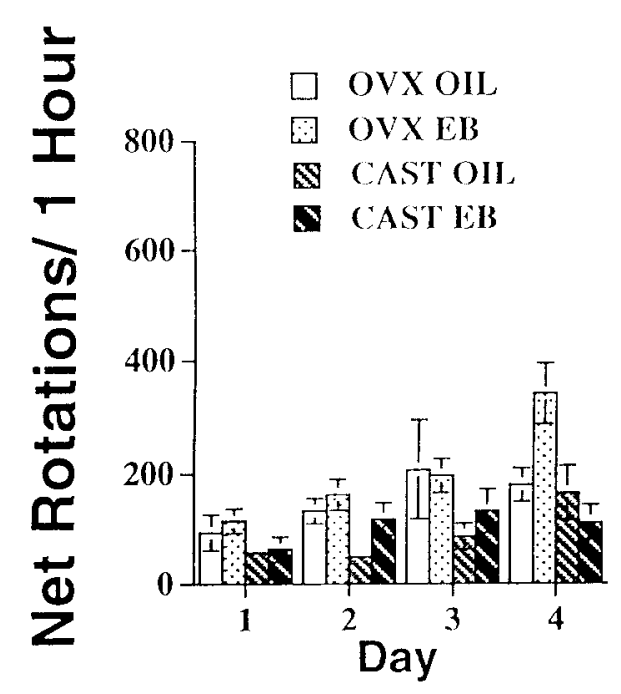

Week 1

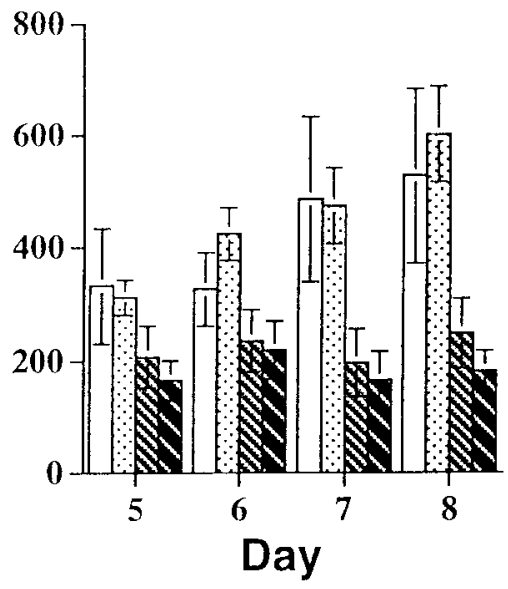

Week 2

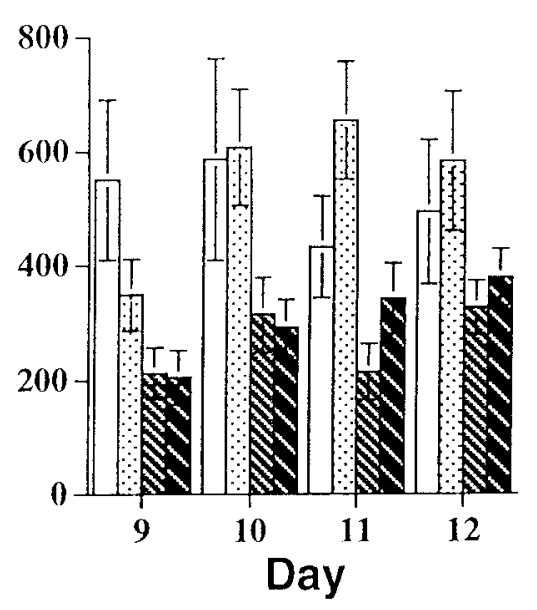

Week 3

FIGURE 2. Sensitization of rotational behavior in animals with unilateral dopamine depletion induced by $15 \mathrm{mg} / \mathrm{kg}$ cocaine in ovariectomized (OVX) or CAST animals treated with either OIL or EB. All groups showed sensitization of this behavior, and two female groups exhibited greater sensitization than did the two male groups. The OVX + EB group exhibited greater sensitization than did all other groups $(p<0.05)$. 
$+\mathrm{EB}, n=11$; CAST + OIL, $n=12$ ). Rotational behavior was recorded for 1 hour after cocaine treatment in automated rotometers. ${ }^{70}$ Animals were tested for 4 consecutive days followed by 3 days without treatment, for total of 12 cocaine treatments.

As illustrated in FIGURE 2, sensitization of rotational behavior also demonstrates the sex differences in sensitization to $15 \mathrm{mg} / \mathrm{kg}$. First, while there was a tendency for the female groups to rotate more than male groups on day 1 , there was no significant effect of group $(\mathrm{F}(3,41)=1.03, p=0.388)$. We also noted that all of the groups showed sensitization of rotational behavior, but the two female groups exhibited greater sensitization than did the males. (Group effect $-\mathrm{F}(3,41)=7.033, p<0.001$; Effect of Time $-\mathrm{F}(11,41)=$ $25.638,<0.001$; Group X Time interaction $\mathrm{F}(33,451)=1.683, p<0.02)$. In post-hoc comparisons, the OVX + EB group exhibited greater rotational behavior than did all other groups when the entire 12 days of behavior are compared $(p<0.05)$. The OVX group exhibited more rotational behavior than did either of the male groups $(p<0.05)$. EB treatment had no effect on rotational behavior or sensitization in the CAST males. Thus, we again see gender differences independent of gonadal hormones and an effect of EB to enhance sensitization in female but not male rats.

\section{CONCLUSIONS}

The evidence reviewed indicates that estrogen has rapid, direct effects on the striatum that act to enhance dopamine release and the behavioral response to psychomotor stimulants in the female rat. Electrophysiological studies suggest that this acute effect of estrogen is indirectly mediated by novel membrane receptors for estradiol. The effect of estrogen on the striatum is sexually dimorphic, in that dopamine activity in the striatum of females is enhanced by estrogen, but dopamine activity in the striatum of male rats is not affected by estrogen.

There are also sexual dimorphisms in the neural systems mediating sensitization to cocaine, in that female rats with or without ovarian hormones show a more rapid rate of sensitization than do males if a particular behavior shows sensitization in the female. However, it is not simply that females are more responsive to the psychomotor stimulants or that they show greater sensitization; there are also qualitative differences in the behaviors invoked by the initial response to these drugs as well as the way in which these behaviors sensitize. Thus, there may be qualitative as well as quantitative sexual dimorphisms in the neural systems mediating the initial response to psychomotor stimulants as well as the responses to repeated drug exposure. 


\section{ACKNOWLEDGMENTS}

This work was supported by grants from the Horace H. Rackham Graduate School and the National Science Foundation (BNS 9816673).

\section{REFERENCES}

1. Wetherington, C.L. \& A.R. Roman, Eds. 1995. Drug Addiction Research and the Health of Women. U.S. Department of Health and Human Services. Rockville, MD.

2. Kandel, D.B., M.P.P. Warner \& R.C. Kessler. 1995. The epidemiology of substance abuse and dependence among women. In Drug Addiction Research and the Health of Women. C.L. Wetherington \& A.R. Roman, Eds: 105-130. U.S. Department of Health and Human Services. Rockville, MD.

3. Kosten, T.R. et al. 1996. Gender differences in response to intranasal cocaine administration to humans. Biol. Psychiatry 39: 147-148.

4. LukAS, S.E. et al. 1996. Sex differences in plasma cocaine levels and subjective effects after acute cocaine administration in human volunteers. Psychopharmacology 125: 346-354.

5. Lynch, W. \& M. CARRoll. 1999. Sex differences in the acquisition of intravenously self-administered cocaine and heroin in rats. Psychopharmacology 144: 77-82.

6. Lindvall, O. \& A. BJorklund. 1974. The organization of the ascending catecholamine neuron systems in the rat brain as revealed by the glyoxylic acid fluorescence method. Acta Physiol. Scand. [Suppl] 412: 1-48.

7. UngerstedT, U. 1971. Striatal dopamine release after amphetamine or nerve degeneration revealed by rotational behavior. Acta Physiol. Scand. 82 (Suppl. 367): 49-68.

8. Arbuthnott, G.W. \& T.J. Crow, 1971. Relation of contraversive turning to unilateral release of dopamine from the nigrostriatal pathway in rats. Exp. Neurol. 30: 484-491.

9. Costall, B. \& R.J. Naylor. 1977. Mesolimbic and extrapyramidal sites for the mediation of stereotyped behavior patterns and hyperactivity by amphetamine and apomorphine in the rat. In Cocaine and Other Stimulants. E.H. Ellinwood \& M.M. Kilbey, Eds: 47-76. Plenum Press. New York.

10. Fink, J.S. \& G.P. Sмiтh, 1980. Relationships between selective denervation of dopamine terminal fields in the naterior forebrain and behavioral responses to amphetamine and apomorphine. Brain Res. 201: 107-127.

11. Ungerstedt, U. 1974. Functional dynamics of central monamine pathways. In The Neurosciences: Third Study Program. F.O. Schmitt \& F.G. Worden, Eds.: 979-988. MIT Press. Cambridge, MA.

12. Robinson, T.E. \& J.B. BeCKer, 1983. The rotational behavior model: asymmetry in the effects of unilateral 6-OHDA lesions of the substantia nigra in rats. Brain Res. 264: 127-131. 
13. Becker, J.B., T.E. Robinson \& K.A. Lorenz. 1982. Sex differences and estrous cycle variations in amphetamine-elicited rotational behavior. Eur. J. Pharmacol. 80: 65-72.

14. Camp, D.M., J.B. Becker \& T.E. Robinson. 1986. Sex differences in the effects of gonadectomy on amphetamine-induced rotational behavior in rats. Behav. Neural. Biol. 46: 491-495.

15. Robinson, T.E., D.M. CAmp \& J.B. Becker. 1981. Gonadectomy attenuates turning behavior produced by electrical stimulation of the nigrostriatal dopamine system in female but not male rats. Neurosci. Lett. 23: 203-208.

16. BECKER, J.B. \& M.E. BEER. 1986. The influence of estrogen on nigrostriatal dopamine activity: behavioral and neurochemical evidence for both pre- and postsynaptic components. Behav. Brain Res. 19: 27-33.

17. BECKER, J.B. 1990. Estrogen rapidly potentiates amphetamine-induced striatal dopamine release and rotational behavior during microdialysis. Neurosci. Lett. 118: 169-171.

18. BECKER, J.B. \& C.N. RUDiCK. 1999. Rapid effects of estrogen or progesterone on the amphetamine-induced increase in striatal dopamine are enhanced by estrogen priming: a microdialysis study. Pharmacol. Biochem. Behav. 64: 53-57.

19. BECKER, J.B. \& J. CHA. 1989. Estrous cycle-dependent variation in amphetamine-induced behaviors and striatal dopamine release assessed with microdialysis. Behav. Brain Res. 35: 117-125.

20. Castner, S.A., L. Xiao \& J.B. Becker. 1993. Sex differences in striatal dopamine: in vivo microdialysis and behavioral studies. Brain Res. 610: 127-134.

21. BECKER, J.B. 1990. Direct effect of $17 \beta$-estradiol on striatum: sex differences in dopamine release. Synapse 5: 157-164.

22. Becker, J.B. \& V.D. Ramirez. 1981. Sex differences in the amphetamine stimulated release of catecholamines from rat striatal tissue in vitro. Brain Res. 204: 361-372.

23. XiaO, L. \& J.B. BeCKER. 1998. Effects of estrogen agonists on amphetaminestimulated striatal dopamine release. Synapse 29: 379-391.

24. Mermelstein, P.G., J.B. Becker \& D.J. Surmeier. 1996. Estradiol reduces calcium currents in rat neostriatal neurons through a membrane receptor. J. Neurosci. 16: 595-604.

25. Коов, G.F. \& F.E. BLOом. 1988. Cellular and molecular mechanisms of drug dependence. Science 242: 715-723.

26. Stewart, J. \& A. BAdiani. 1993. Tolerance and sensitization to the behavioral effects of drugs. Behav. Pharmacol. 4: 289-312.

27. JAFFE, J.H. 1990. Drug addiction and drug abuse. In The Pharmacological Basis of Therapeutics. A.G. Gilman et al., Eds: 522-573. Pergamon Press. New York.

28. Tiffany, S.T. 1990. A cognitive model of drug urges and drug-use behavior: role of automatic and nonautomatic processes. Psychol. Rev. 97: 147-168.

29. WAtSON, S.J. et al. 1989. Neuroanatomical and neurochemical substrates of drug-seeking behavior: overview and future directions. In Molecular and Cellular Aspects of the Drug Addictions. A. Goldstein, ed. :29-91. Springer-Verlag. New York.

30. Wise, R.A. \& M.A. Bozarth. 1987. A psychomotor stimulant theory of addiction. Psychol. Rev. 94: 469-492.

31. BERRIDGE, K.C. \& T.E. Robinson. 1995. The mind of an addicted brain: neural sensitization of wanting versus liking. Curr. Direct. Psychol. Sci. 4: 71-76. 
32. Deminiere, J.M. et al. 1989. Experimental approach to individual vulnerability to psychostimulant addiction. Neurosci. Biobehav. Rev. 13: 141-147.

33. Horger, B.A., K. Shelton \& S. Schenk. 1990. Preexposure sensitizes rats to the rewarding effects of cocaine. Pharm. Biochem. Behav. 37: 707-711.

34. Horger, B.A., M.K. Giles \& S. Schenk. 1992. Preexposure to amphetamine and nicotine predisposes rats to self-administer a low dose of cocaine. Psychopharmacology 107: 271-276.

35. LETT, B.T. 1989. Repeated exposures intensify rather than diminish the rewarding effects of amphetamine, morphine, and cocaine. Psychopharmacology (Berl.) 98: 357-362.

36. PIAzZA, P.V. et al. 1991. Individual vulnerability to drug self-administration: action of corticosterone on dopaminergic systems as a possible pathophysiological mechanism. In The Mesolimbic Dopamine System: From Motivation to Action. P. Willner \& J. Scheel-Krüger, Eds..: 473-495. John Wiley \& Sons Ltd. New York.

37. Robinson, T.E. 1993. Persistent sensitizing effects of drugs on brain dopamine systems and behavior: implications for addiction and relapse. In Biological Basis of Substance Abuse. S.G. Korenman \& J.D. Barchas, Eds.: 373-402. Oxford University Press. New York.

38. Robinson, T.E. \& K.C. Berridge. 1993. The neural basis of drug craving: an incentive-sensitization theory of addiction. Brain Res. Rev. 18: 247-291.

39. Schenk, S. et al. 1992. Blockade of sensitizing effects of amphetamine preexposure on cocaine self-administration by the NMDA antagonist MK-801. Soc. Neurosci. Abstr. 18: 1237.

40. Kalivas, P.W. \& J. Stewart. 1991. Dopamine transmission in the initiation and expression of drug- and stress-induced sensitization of motor activity. Brain Res. Rev. 16: 223-244.

41. Robinson, T.E. et al. 1985. Enduring enhancement in frontal cortex dopamine utilization in an animal model of amphetamine psychosis. Brain Res. 343: 374-347.

42. Robinson, T.E. 1984. Behavioral sensitization: characterization of enduring changes in rotational behavior produced by intermittent injections of amphetamine in male and female rats. Psychopharmacology (Berl.) 84: 466-475.

43. Shippenberg, T.S. \& C. Heidbreder. 1995. Sensitization to the conditioned rewarding effects of cocaine: pharmacological and temporal characteristics. J. Pharmacol. Exp. 273: 808-815.

44. Shippenberg, T.S., C. Heidbreder \& A. Lefevour. 1996. Sensitization to the conditioned rewarding effects of morphine: pharmacology and temporal characteristics. Eur. J. Pharmacol. 299: 33-39.

45. Shippenberg, T.S., A. Lefevour \& C. Heidbreder. 1996. k-opioid receptor agonists prevent sensitization to the conditioned rewarding effects of cocaine. J. Pharmacol. Exp. Ther. 276: 545-554.

46. PiazZA, P.V. et al. 1989 . Factors that predict individual vulnerability to amphetamine self-administration. Science 245: 1511-1513.

47. PiazZA, P.V. et al. 1990. Stress- and pharmacologically-induced behavioral sensitization increases vulnerability to acquisition of amphetamine selfadministration. Brain Res. 514: 22-26.

48. Woolverton, W.L., L.I. GoldberG \& J.Z. Ginos. 1984. Intravenous selfadministration of dopamine receptor agonists by rhesus monkeys. J. Pharmacol. Exp. Ther. 230: 678-683. 
49. Pierre, P. \& P. Vevina. 1997. Predisposition to self-administer amphetamine: the contribution of response to novelty and prior exposure to the drug. Psychopharmacology 129: 277-284.

50. Valadez, A. \& S. Schenk. 1994. Persistence of the ability of amphetamine preexposure to facilitate acquisition of cocaine self-administration. Pharmacol. Biochem. Behav. 47: 203-205.

51. RoBinson, T.E. \& J.B. BECKER. 1986. Enduring changes in brain and behavior produced by chronic amphetamine administration: a review and evaluation of animal models of amphetamine psychosis. Brain Res. 396: 157-198.

52. Paulson, P.E., D.M. CAmp \& T.E. Robinson. 1991. Time course of transient behavioral depression and persistent behavioral sensitization in relation to regional brain monoamine concentrations during amphetamine withdrawal in rats. Psychopharmacology (Berl.) 103: 480-492.

53. Henry, D.J. \& F.J. White. 1995. The persistence of behavioral sensitization to cocaine parallels enhanced inhibition of nucleus accumbens neurons. J. Neurosci. 15: 6287-6299.

54. JANAK, P.A. et al. 1997. Rapid decay of cocaine-induced behavioral sensitization of locomotor behavior. Behav. Brain Res. 88: 195-199.

55. SirCAR, R. \& D. KIM. 1999. Female gonadal hormones differentially modulate cocaine-induced behavioral sensitization in Fischer, Lewis and Sprague-Dawley rats. J. Pharmacol. Exp. Ther. 289: 54-65.

56. Post, R.M., S.R. Weiss \& A. Pert. 1987. The role of context and conditioning in behavioral sensitization to cocaine. Psychopharmacol. Bull. 23: 425-429.

57. Segal, D.S. \& M.A. SchuCKIT. 1983. Animal models of stimulant-induced psychosis. In Stimulants: Neurochemical, Behavioral and Clinical Perspectives. I. Creese, ed. :131-167. Raven Press. New York.

58. Segal, D.S. \& R. KuCZENSKI. 1994. Behavioral pharmacology of amphetamine. In Amphetamine and Its Analogs: Psychopharmacology, Toxicology and Abuse. A.K. Cho \& D.S. Segal, Eds.: 115-150. Academic Press, Inc. San Diego.

59. White, F.J. \& M.E. Wolf. 1991. Psychomotor stimulants. In The Biological Bases of Drug Tolerance and Dependence. J. Pratt, ed. :153-197. Academic Press. New York.

60. Robinson, T.E. 1988. Stimulant drugs and stress: factors influencing individual differences in the susceptibility to sensitization. In Sensitization of the Nervous System. P.W. Kalivas \& C. Barnes, Eds.: 145-173. Telford Press. Caldwell, NJ.

61. Robinson, T.E. 1991. The neurobiology of amphetamine psychosis: evidence from studies with an animal model. In Taniguchi Symposia on Brain Sciences, Vol. 14. Biological Basis of Schizophrenia. T. Nakazawa, ed. :185201. Japan Scientific Societies Press. Tokyo.

62. Camp, D.M. \& T.E. Robinson. 1988. Susceptibility to sensitization. II. The influence of gonadal hormones on enduring changes in brain monoamines and behavior produced by the repeated administration of $\mathrm{D}$-amphetamine or restraint stress. Behav. Brain Res. 30: 69-88.

63. CAMP, D.M. \& T.E. Robinson. 1988. Susceptibility to sensitization. I. Sex differences in the enduring effects of chronic D-amphetamine treatment on locomotion, stereotyped behavior and brain monoamines. Behav. Brain Res. 30: 55-68. 
64. Robinson, T.E., J.B. Becker \& S.K. Presty. 1982. Long-term facilitation of amphetamine-induced rotational behavior and striatal dopamine release produced by a single exposure to amphetamine: sex differences. Brain Res. 253: 231-241.

65. van HaAren, F. \& M. Meyer. 1991. Sex differences in the locomotor activity after acute and chronic cocaine administration. Pharmacol. Biochem. Behav. 39: 923-927.

66. Forgie, M.L. \& J. Stewart. 1994. Sex difference in amphetamine-induced locomotor activity in adult rats: role of testosterone exposure in the neonatal period. Pharmacol. Biochem. Behav. 46: 637-645.

67. Bowman, B.P. et al. 1999. Effects of sex and gonadectomy on cocaine metabolism in the rat. J. Pharm. Exp. Ther. 290: 1316-1323.

68. PERIS, J. et al. 1991. Estradiol enhances behavioral sensitization to cocaine and amphetamine-stimulated $\left[{ }^{3} \mathrm{H}\right]$ dopamine release. Brain Res. 566: 255-264.

69. Curran, E.J., R.L. Albin \& J.B. Becker. 1993. Adrenal medulla grafts in the hemiparkinsonian rat: profile of behavioral recovery predicts restoration of the symmetry between the two striata in measures of pre- and postsynaptic dopamine function. J. Neurosci. 13: 3864-3877.

70. McFarlane, D.K., B.J. Martonyi \& T.E. Robinson. 1992. An inexpensive automated system for the measurement of rotational behavior in small animals. Behav. Res. Meth. Inst. \& Computers 24: 414-419. 